\title{
Article \\ Public Transportation Service Quality Evaluation during the COVID-19 Pandemic in Amman City Using Integrated Approach Fuzzy AHP-Kendall Model
}

\author{
Ahmad Alkharabsheh *(D) and Szabolcs Duleba (D) \\ Department of Transport Technology and Economics, Budapest University of Technology and Economics, \\ Stoczek u. 2, H-1111 Budapest, Hungary; duleba.szabolcs@mail.bme.hu \\ * Correspondence: kharabsheh@edu.bme.hu
}

Citation: Alkharabsheh, A.; Duleba,

S. Public Transportation Service

Quality Evaluation during the

COVID-19 Pandemic in Amman City Using Integrated Approach Fuzzy AHP-Kendall Model. Vehicles 2021, 3, 330-340. https://doi.org/

$10.3390 /$ vehicles3030020

Academic Editor: Yongzhi Zhang

Received: 4 June 2021

Accepted: 24 June 2021

Published: 29 June 2021

Publisher's Note: MDPI stays neutral with regard to jurisdictional claims in published maps and institutional affiliations.

Copyright: (c) 2021 by the authors. Licensee MDPI, Basel, Switzerland. This article is an open access article distributed under the terms and conditions of the Creative Commons Attribution (CC BY) license (https:// creativecommons.org/licenses/by/ $4.0 /)$.

\begin{abstract}
The COVID-19 pandemic has affected public transportation worldwide, and its implications need to be evaluated and study deeply on all public transportation aspects. Therefore, an analysis has been created to examine the effects of the pandemic on public transportation service quality decisions to have a better vision of the different stakeholders' needs to keep the system functioning in a profitable way. Stakeholder participation in complex, multi-criteria decision-making often produces very different results in prioritizing the decision attributes. Rank correlation techniques generally measure the degree of agreement or non-agreement among the evaluator groups. However, the multi-criteria methodology can determine not only ordinal but also cardinal priorities. Consequently, except for the attributes' positions, the weight values are also significant in the final decision. This paper aims to apply a more sophisticated measure of group agreement than rank correlation. First, the Fuzzy-hierarchical analytical process (FAHP) has been used to find out the aggregated weights, then the Kendall correlation values are computed to reveal stakeholder opinions. Finally, the agreement measure approach has been tested in a real-world case study: the public transport development decision of Amman, Jordan. The analysis shows that by applying the Kendall technique, Kendall could gain a more profound insight into the priority characteristics of different evaluator groups.
\end{abstract}

Keywords: Fuzzy AHP; Kendall-W; public transportation; transport planning; MCDM

\section{Introduction}

The COVID-19 pandemic has affected all sectors, including the public transportation system. Unlike the usual behavior of governments to incentivize people to use public transportation, it has started to motivate people to use their cars during the pandemic. In contrast, measures were taken such as curfew, social distancing, and other measures to minimize the virus's spread. During the pandemic, countries faced the challenge associated with ordinary travel, calling for the requalification of current road infrastructure and transit systems - the unconventional design of roads and the enhancement of pedestrian and bicycle lanes ways of reinforcement mobility after the pandemic. Additionally, the COVID19 pandemic has raised some concerns about infrastructure vision, causing everyone's perspective to shift. However, the economic system and transportation demand can be improved and expanded through short and long-term planning, the acquisition of public funding, and facilitate public-private partnerships. Moreover, the long-term effects of the COVID-19 pandemic may encourage more permanent changes in intelligent working and other daily activities, lowering mobility requirements and overall fossil energy use. These developments can accelerate sustainability transitions by promoting research and new practices resulting from the COVID-19 pandemic [1].

Public transportation in Amman has been adversely affected because individuals or small companies own the public buses, economic implications have arisen directly on the owners and passengers. This paper introduces an integrated approach, Fuzzy 
AHP-Kendall model, combining decision-makers demands to present a sustainable transit system. The conducted model has been tested in the city of Amman in Jordan during the COVID-19 pandemic period on surveying the local public bus transport service quality and its desired modification by the passengers, non-passengers, and municipal officials.

In transport sciences, conflicting stakeholder groups and practices are often identified, and the level of their agreement could be a vital indicator of a planned or implemented decision. Diversity in preferences might cause the punishment of one or more stakeholder groups, making the intervention to transport system unsustainable in the long term.

However, what should we call the diversity of evaluator groups in preference surveys? What could be the best way to measure and indicate the degree of alterations in a priority ranking of transport-related decision attributes?

In value and utility-based multi-criteria decision-making methods: Analytic Hierarchy Process [2], Analytic Network Process [3], Best-Worst Method [4], Simple Multi-Attribute Rating Technique [5], and Swing [6], the outcomes are both ordinal and cardinal.

Despite this, the existing scientific solution for determining the degree of agreement among evaluator groups focuses merely on comparing rankings, thus on the ordinal characteristic of MCDM outcomes. Kendall or Spearman rank correlation techniques applied for agreement measures depend on the number of stakeholders. Even the most recent and advanced models [7] concentrate on the rankings themselves as outcomes. Still, the weight values or alternative scores are neglected in the agreement measure and consensus creation procedure.

The process of decision-making often needs to be improved, and tools to facilitate decision making. Consequently, MCDM techniques have been developed to facilitate decision-makers' work.

Scholars from different fields have used MCDM techniques to solve decision-making problems. For instance, ref. [8] applied the Analytic Hierarchy Process (AHP) to improve the public transport sector's performance by enhancing the performance of regional urban operators. Ref. [9] used the AHP to improve urban public transport system decision problems in a developing country. At the same time, ref. [10] applied the Delphi method, GAHP, PROMETHEE to evaluate the public transportation systems in Tehran city, ref. [11] revised the PROMETHEE approach in the public transportation sector, ref. [12] combined the Analytic Hierarchy Process (AHP) and Interpretive Structural Modeling (ISM) to amend passenger preferences and expert knowledge on transport systems. Ref. [13] built a hybrid method for integrating demand forecasts to apply it in the automotive industry. Ref. [14] used Pareto optimality with the Analytic Hierarchy Process (AHP) in public transport service development. Ref. [15] conducted an AHP application to select the vendors of the telecommunications system. Ref. [16] proposed a new MCDM technique Gray-AHP decision-making method to evaluate the public transportation supply quality. Ref. [17] applied AHP-BWM to assess driver behavior factors. While, different researchers $[18,19]$ are trying to affect the decisions by using policy models and simulation studies.

Multi-criteria decision techniques (MCDM) have become popular to solve and support transportation field decision problems. For example, ref. [20] applied a hybrid approach based on the Analytical Hierarchy Process (AHP) and Dempster Shafer theory to evaluate the impact of environment-friendly transport measures. Ref. [21] used an MCDM approach for selecting a sustainable transport system. Ref. [22] developed a sustainable transport policy using the AHP approach by testing several transport policies and strategies. Ref. [23] used MCDM and IPA in the transshipment sector to assess the quality of the international port. Ref. [24] used Fuzzy MCDM to evaluate the service quality in the airports.

Jordan's commercial, political, and cultural capital is Amman. It is located in a strategic region in the Middle East. It is home to 4 million people, including moreover 42 percent Jordanians and individuals of various ethnicities. Jordan is one of the countries with the most considerable number of refugees [25]. This humanitarian behavior has significant consequences for Amman, Jordan's capital, especially on the infrastructure components in Amman, precisely the public transportation sector, due to the lack of readiness to host the 
high number of refugees. Therefore, a reliable, sustainable transportation system is needed. Traffic and public transportation have become the main concern for citizens. Boosting the city's economic situation is necessary to minimize the financial burden by improving and investing in the public transportation sector. Consequently, the economic crisis will be positively changed. For example, the job market access and business district will increase the laborers' income and business productivity [26]. Investing in the public transportation sector will attempt more tourists to visit Jordan, which will be reflected in the country's economy directly and indirectly (by creating new jobs) [27]. Researchers are studying traffic to improve citizens' lives, minimize congestion, and lower the accident rate [28]. Jordan has vast human, economic losses and social and emotional negative impacts. Accordingly, improving the public transportation system will improve the traffic in the city. For instance, ref. [29] worked on travel costs and time delays for public transport in Jordan. In contrast, government action has been taken to implement the Sustainable Urban Mobility Plan (SUM) for Amman city to have a strategic mobility plan of the town [30] and build a bus rapid transit (BRT) project to improve the public transportation in the capital. Ref. [31] introduced a new integrated model to support the decision-maker to improve public bus transportation in the city by using an integrated AHP-BWM model.

The rest of the paper is structured as follows: In the next section, we provide the description of Fuzzy AHP and the existing and proposed concordance calculation techniques. Further, a case study on a public transport development decision in the Jordan capital, Amman, is presented applying the new concordance calculation.

Finally, some conclusions are drawn, and suggestions are made to apply further and improve the new approach.

\section{Materials and Methods}

\subsection{Main Characteristics of Fuzzy AHP}

FAHP approach was extensively applied by academics and professionals in many fields and problems, mainly in engineering fields like transport engineering field [32,33].

This study emphasizes and ranks in Amman the criteria for the quality of public transport identified by the Fuzzy AHP approach. As a result, the FAHP method was used to fuzzify the hierarchical analysis by allowing fuzzy numbers for the evaluators' pairwise comparisons (P.C.s). As a result, the hierarchy tree must establish P.C.s among the four main criteria and twenty-four sub-criteria. Following data collection, the geometric mean approach was used to aggregate evaluators' responses, and final scores were computed and prioritized. A consistency check was performed to ensure the quality and trustworthiness of the collected data.The mathematical notation for the FAHP evaluation was used from the work of Sun [34]. The author conducted a fuzzy logic technique in the referred paper by developing a reconnaissance survey with fuzzy triangular scales. The following formulas are simple applications in our research for the newly created integrative decision model. They introduce the formulas in detail to give insight into the computational process.

A fuzzy number $\widetilde{T}$ on $\mathrm{R}$ to be a triangular fuzzy number if its membership function $\mu_{\widetilde{T}}(x): R \rightarrow[0,1]$ is equal to the Formula (1):

$$
\mu_{\widetilde{A}}(x)=\left\{\frac{x-s}{m-s}, s \leq x \leq m \frac{r-x}{r-m}, m \leq x \leq r 0,\right.
$$

Otherwise, from Equation (1), $d$ and $u$ intend the inferior and superior bounds of the fuzzy number $\widetilde{T}$, and $m$ is the modal value for $\widetilde{T}$ (see Figure 1 ). The fuzzy triangular number can be exhibited by $\widetilde{T}=(s, m, r)$. 


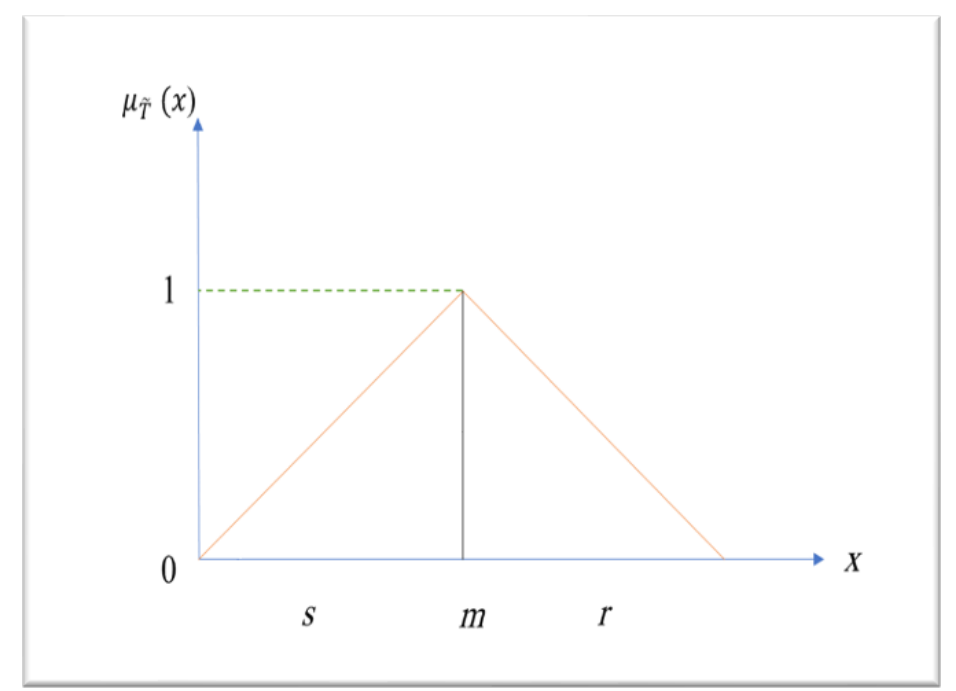

Figure 1. The membership functions of the triangular fuzzy number.

The operational laws of triangular fuzzy number $\widetilde{T}_{1}=\left(s_{1}, m_{1}, r_{1}\right)$ and $\widetilde{T}_{2}=$ $\left(s_{2}, m_{2}, r_{2}\right)$ are blazon as consecutive formulas as an addition (2), multiplication (3), division (4), and reciprocal (5) of the fuzzy numbers.

In our procedure, all formulas were applied.

The aggregation of $\widetilde{T}_{1}$ and $\widetilde{T}_{2}$ is in Equation (2):

$$
\widetilde{T}_{1} \oplus \widetilde{T}_{2}=\left(s_{1}+s_{2}, m_{1}+m_{2}, r_{1}+r_{2}\right) \text {. }
$$

The multiplying of $\widetilde{T}_{1}$ and $\widetilde{T}_{2}$ is in Equation (3):

$$
\widetilde{T}_{1} \bigotimes \widetilde{T}_{2}=\left(s_{1} s_{2}, m_{1} m_{2}, r_{1} r_{2}\right) \text { for } s_{1}, s_{2}>0 ; m_{1}, m_{2}>0 ; r_{1} r_{2}>0 \text {. }
$$

The division of fuzzy number $\varnothing$ shown in the following Equation:

$$
\widetilde{T}_{1} \varnothing \widetilde{T}_{2}=\left(\frac{s_{1}}{r_{2}}, \frac{m_{1}}{m_{2}}, \frac{r_{1}}{s_{2}}\right) \text { for } s_{1}, s_{2}>0 ; m_{1}, m_{2}>0 ; r_{1} r_{2}>0 \text {. }
$$

The reciprocal of the fuzzy number shown in the following Equation:

$$
\widetilde{T}^{-1}=\left(s_{1}, m_{1}, r_{1}\right)^{-1}=\left(\frac{1}{r_{1}}, \frac{1}{m_{1}}, \frac{1}{s_{1}}\right) \text { for } s_{1}, s_{2}>0 ; m_{1}, m_{2}>0 ; r_{1} r_{2}>0 .
$$

In the current research, the computational technique was based on the sequent fuzzy numbers defined by Gumus [35] and Sun [34].

Figure 2 represents the public transport service quality elements. Considering that the decision elements' supreme connections are hierarchical, and there are very few dependencies among the attributes. The basic hierarchical structure made it possible to apply FAHP. FAHP methodology was followed in constructing the questionnaire. For the first level, the questions were asked: Compare the importance of improvement for the approachability and directness criterion, and so forth for all possible pairs. Consequently, for the second level, the same procedure was followed. The same questionnaire was presented to all stakeholders (passengers, non-passengers, and municipal officials). 


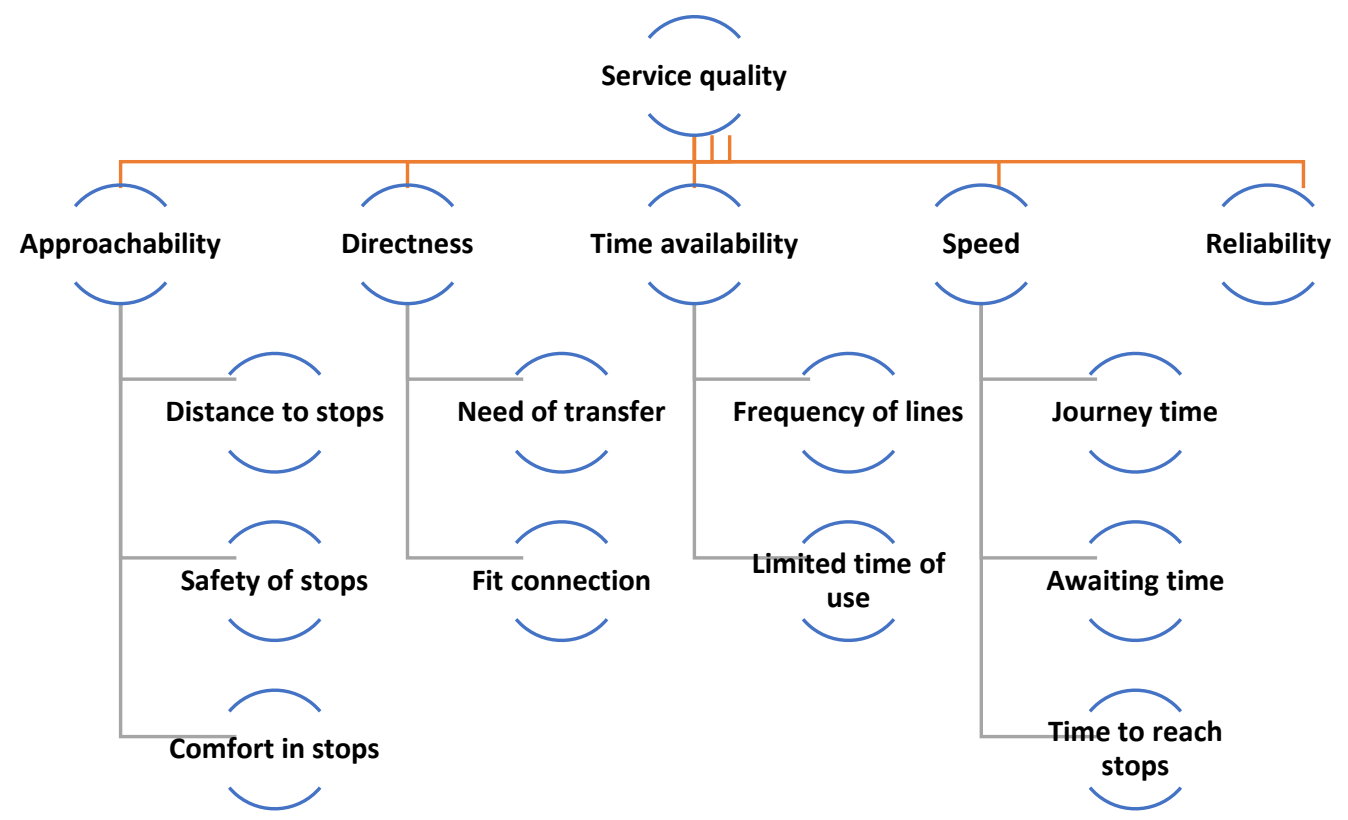

Figure 2. The hierarchical model of the service quality.

Passengers: The traveler or potential traveler uses the public buses on a daily, weekly, or monthly basis.

Non-Passengers: people using their private cars to move, but potential passengers in the future.

Municipal officials: The municipality representatives in the transport department.

The number of participants in this survey was 50 passengers, 30 non-passengers, and 10 municipal officials.

Table 1 shows the fuzzy scale numbers and their definition for each group. The employed P.C. matrices were formed based on the hierarchical structure of criteria, as shown in Figure 1. Linguistic terms were allocated to the P.C.s by asking which criteria are more treasured than the other concerning the primary goal. As

$$
\tilde{T}=\tilde{A}=\left[\begin{array}{ccccc}
1 & \tilde{a}_{12} & \tilde{a}_{13} & \tilde{a}_{14} & \tilde{a}_{15} \\
\tilde{a}_{21} & 1 & \tilde{a}_{23} & \tilde{a}_{24} & \tilde{a}_{25} \\
\tilde{a}_{31} & \tilde{a}_{32} & 1 & \tilde{a}_{34} & \tilde{a}_{35} \\
\tilde{a}_{41} & \tilde{a}_{42} & \tilde{a}_{43} & 1 & \tilde{a}_{45} \\
\tilde{a}_{51} & \tilde{a}_{52} & \tilde{a}_{53} & \tilde{a}_{54} & 1
\end{array}\right]=\left[\begin{array}{ccccc}
1 & \tilde{a}_{12} & \tilde{a}_{13} & \tilde{a}_{14} & \tilde{a}_{15} \\
1 / \tilde{a}_{12} & 1 & \tilde{a}_{23} & \tilde{a}_{24} & \tilde{a}_{25} \\
1 / \tilde{a}_{13} & 1 / \tilde{a}_{23} & 1 & \tilde{a}_{34} & \tilde{a}_{35} \\
1 / \tilde{a}_{14} & 1 / \tilde{a}_{24} & 1 / \tilde{a}_{34} & 1 & \tilde{a}_{45} \\
1 / \tilde{a}_{15} & 1 / \tilde{a}_{25} & 1 / \tilde{a}_{35} & 1 / \tilde{a}_{45} & 1
\end{array}\right]
$$

where

$$
\tilde{a}_{i j}=\left\{\tilde{q}^{-1}, \tilde{8}^{-1}, \tilde{7}^{-1}, \tilde{\sigma}^{-1}, \tilde{\sim}^{-1}, \tilde{4}^{-1}, \tilde{3}^{-1}, \tilde{2}^{-1}, \tilde{1}, \tilde{2}, \widetilde{3}, \tilde{4}, \tilde{5}, \tilde{6}, \tilde{7}, \tilde{8}, \tilde{9}, 1, i \neq j 1 i=j\right.
$$

The fuzzy geometric mean technique was implemented for accumulating the fuzzy weights for each rater group [36].

$$
\begin{gathered}
\tilde{r}_{i}=\left(\widetilde{a}_{i 1} \bigotimes \tilde{a}_{i 2} \bigotimes \tilde{a}_{i 3} \bigotimes \tilde{a}_{i 4} \bigotimes \tilde{a}_{i 5}\right)^{1 / n} . \\
\widetilde{w}_{i}=\widetilde{r}_{i}\left[\widetilde{r}_{1} \oplus \widetilde{r}_{2} \oplus \widetilde{r}_{3} \oplus \widetilde{r}_{4} \oplus \widetilde{r}_{5}\right]^{-1} .
\end{gathered}
$$

where $\widetilde{a}_{i j}$ is fuzzy comparison value of dimension $i$ to criterion $j$, thus, $\widetilde{r}_{i}$ It is a G.M. technique of fuzzy comparison value of criterion $i$ to each criterion.

$\widetilde{w}_{i}$ is the fuzzy weight of the $i$ th criterion, which is illustrated by a triangular fuzzy number, $\widetilde{w}_{i}=\left(d w_{i}, m w_{i}, h w_{i}\right)$. The $l w_{i}, m w_{i}$, and $u w_{i}$ Emblematic the upper, middle, and lower values of the fuzzy weight of the $i$-th dimensions. 
Table 1. Linguistic scale of the scale fuzzy numbers.

\begin{tabular}{ccc}
\hline F.N. & Linguistic Scale & F.N. Scale \\
\hline 9 & Perfect & $(8,9,10)$ \\
\hline 8 & Absolute & $(7,8,9)$ \\
\hline 7 & Very good & $(6,7,8)$ \\
\hline 6 & Fairly good & $(5,6,7)$ \\
\hline 5 & Good & $(4,5,6)$ \\
\hline 4 & Preferable & $(3,4,5)$ \\
\hline 3 & Not bad & $(2,3,4)$ \\
\hline 2 & Weakly Important & $(1,2,3)$ \\
\hline 1 & Equally Important & $(1,1,1)$ \\
\hline
\end{tabular}

The consistency ratio for all pairwise comparison (P.C.) matrices was smaller than 0.1, which is acceptable for completing the Fuzzy AHP analysis, as Saaty suggested [37]. The final scores of the eigenvectors provide the opportunity to set up a rank order of preferences for the participants of public bus transport on the issues of the system also considering the weight scores of the previous levels by using the following Equation:

$$
\widetilde{w}_{A_{i}}=\frac{\widetilde{w}_{j}}{\widetilde{w}} \frac{\widetilde{w}_{i j}}{\sum_{k=1}^{n} \widetilde{w}_{i k}}=\left(\frac{\widetilde{w}_{j}}{\widetilde{w}} \frac{1}{\sum_{k=1}^{n} \widetilde{w}_{i k}}\right) \widetilde{w}_{i j} .
$$

where $j=1, \ldots, m$ and $\widetilde{w}=\sum_{i=1}^{m} \widetilde{w}_{j}$;

$\widetilde{w}_{j}>0(j=1, \ldots, m)$ represents the related weight coordinate from the previous level.

$\widetilde{w}_{i j}>0(i=1, \ldots, n)$ is the eigenvector computed from the matrix in the current level.

$\widetilde{w}_{A i}(i=1, \ldots, n)$ is the calculated weight score of the current level's elements.

\subsection{Kendall Concordance Characteristics}

As previously mentioned, the purpose of this conducted research has been to collect preference scores related to public bus transport development and analyze the variation among the opinions of the three distinguished evaluator stakeholders. These viewpoints are expressed by the previously introduced $w_{A i}$. Final scores (9) gained the group wisely. However, it needs to be stressed that for such cases, where harmonious groups can be separated in the evaluation process with different interests, expertise, etc., the aggregation Equation (5) can only be applied within the homogeneous group, but not among groups. For example, in the case of Amman (introduced in the Results section), three nearly homogeneous groups:

Passengers, non-passengers, and municipal officials' representatives could be separated. Then, Equation (5) was applied among the groups wisely. By this, the application of AHP could demonstrate each group's preferences: four distinct rankings of supply quality elements could be obtained that reflected the importance scores of each decision-maker group related to the necessity of developing the public transport system items. Finally, to assess the agreement degree or concordant degree among passengers, non-passengers, and municipal officials', Kendall's concordance coefficient (W) has been applied [38]. This is a nonparametric method for three or more different rankings and applicable for evaluating the agreement among multiple involving groups.

$$
R_{i}=\sum_{j=1}^{m} r_{i j}
$$


where $R_{i}$ the total aggregated ranking for each criterion $i, r_{i j}$. The rank given to criterion $i$ by the participant group $j, m$ is the number of rater groups rating $\mathrm{n}$ factors.

$$
\begin{gathered}
R_{i}=\frac{m(n+1)}{2} \\
S=\sum_{j=1}^{n}\left(R_{i}-R\right)^{2}
\end{gathered}
$$

where $S$ is a sum-of-squares statistic deviation over the row sums of ranking $R_{i}$ and $R$ is the mean of the Ri values. Following that, Kendall's " $W$ " statistic is between one and zero, and it can be obtained from either of the following formulas:

$$
W=\frac{12 S}{m^{2}\left(n^{3}-n\right)}
$$

After applying the Formula, the result will be a number that determines the agreement degree among the different groups, as shown in Table 2.

Table 2. Kendall's W agreement degree scale.

\begin{tabular}{cc}
\hline $\boldsymbol{W}$ & Interpretation \\
\hline 0 & No agreement \\
0.10 & Weak agreement \\
0.30 & Moderate agreement \\
0.60 & Strong agreement \\
1 & Perfect agreement \\
\hline
\end{tabular}

\section{Results}

\subsection{Case Study}

Amman, the capital of Jordan, has a strategic location in the middle east. In contrast, this location has to be exploited more to attract businesses and entrepreneurs by improving the public transportation network, enhancements needed at the levels of law and regulations, and the transportation network level. Being eager to improve the whole system will affect the economic situation of the city positively. For instance, tourism will be raised if you have a sound transportation system to have no trouble moving around the city without getting scammed by private car companies [39]. On the other side, accessibility to the markets and job places will be more comfortable and smoother without any congestion. Accordingly, employers and employees will benefit from the transportation network. Complex decisions that need to be taken to have a successful system include the physical network and the legislation and laws to regulate the whole transport process [40]. This paper attempts to demonstrate a new decision-making approach, which has been proposed to support decision-makers to make the right choice related to the transportation network's improvements. Amman only has a public bus system, and the study will cover the public bus system and grasp its primary issue.

\subsection{Result}

This section presents the results of the analyzed data.

Table 3 demonstrates the stakeholders' preferences for level 1. It is clearly shown that the passengers and officials groups agree that the "Speed" criterion must be in the first place of the improvements. While non-passengers had the "Time availability" criterion in the first place to be improved, the stakeholders have different preferences in level 1, which undoubtedly affects the level 2 ranking and score. Accordingly, raising the number of buses for each routing will improve the speed and satisfy the passengers and municipal officials and compensate for the damage done by reducing passengers per trip during the pandemic. In addition, exclusive lanes for the public buses would decrease the waiting time. However, "Time availability " became in the first position from the non-passengers group point of 
view in terms of importance. Accordingly, operation hours extension would enhance the public bus in the city. Interestingly, the priorities for stakeholders that need to be placed in the first level have changed during the pandemic. For instance, in our previous studies in 2019,2020 , respectively $[9,31]$, passengers had the safety of travel attribute in the first place to be improved. At the same time, now speed criterion is the priority for passengers.

Table 3. Stakeholders final weight score for level 1.

\begin{tabular}{ccccccc}
\hline Criteria & $\begin{array}{c}\text { Passengers } \\
\text { Final Weight }\end{array}$ & $\begin{array}{c}\text { Passengers } \\
\text { Rank }\end{array}$ & $\begin{array}{c}\text { Non-Passengers } \\
\text { Final Weight }\end{array}$ & $\begin{array}{c}\text { Non-Passengers } \\
\text { Rank }\end{array}$ & $\begin{array}{c}\text { Municipal Officials } \\
\text { Final Weight }\end{array}$ & $\begin{array}{c}\text { Municipal Officials } \\
\text { Rank }\end{array}$ \\
\hline Approachability & 0.0628 & 5 & 0.0775 & 5 & 0.0628 & 5 \\
\hline Directness & 0.0980 & 4 & 0.1032 & 4 & 0.0980 & \\
\hline Time availability & 0.3102 & 2 & 0.3624 & 1 & 0.3102 & \\
\hline Speed & 0.3661 & 1 & 0.2976 & 2 & 0.3661 & \\
\hline Reliability & 0.1629 & 3 & 0.1593 & 3 & 0.1629 & 3 \\
\hline
\end{tabular}

Table 4 demonstrates the preferences for all stakeholders for level 2. The criterion "Journey Time" is the essential criterion for the passengers group, "Frequency of lines" is the critical attribute that needs to be improved based on the non-passengers group. In contrast, the "Limited time if use" attribute was the municipal officials' concern. As there is no agreed decision at the first level between decision-makers, different preferences are expected at level 2. Still, at the same time, this is good for conducting a strategical traffic master plan for the city by including the priority attributes that need development and improvement to work on it early instead of working without clear baselines. COVID-19 new regulations and restrictions have changed the priorities for municipal officials, for example, in the 2020 study [31]. Their focus was to improve the fit connection criterion, while now their best interest to improve the limited time of use attribute in the first place as the pandemic affected this criterion.

Table 4. Stakeholders final weight score for level 2.

\begin{tabular}{|c|c|c|c|c|c|c|}
\hline Criteria & $\begin{array}{l}\text { Passengers } \\
\text { Final Weight }\end{array}$ & $\begin{array}{l}\text { Passengers } \\
\text { Rank }\end{array}$ & $\begin{array}{l}\text { Non-Passengers } \\
\text { Final Weight }\end{array}$ & $\begin{array}{c}\text { Non-Passengers } \\
\text { Rank }\end{array}$ & $\begin{array}{l}\text { Municipal Officials } \\
\text { Final Weight }\end{array}$ & $\begin{array}{c}\text { Municipal Officials } \\
\text { Rank }\end{array}$ \\
\hline Distance to stop & 0.0315 & 8 & 0.0377 & 8 & 0.0261 & 8 \\
\hline Safety of Stops & 0.0183 & 9 & 0.0228 & 9 & 0.0175 & 9 \\
\hline Comfort of stops & 0.0130 & 10 & 0.0170 & 10 & 0.0192 & 10 \\
\hline Journey time & 0.1831 & 1 & 0.1473 & 3 & 0.1431 & 2 \\
\hline Awaiting time & 0.0631 & 5 & 0.0471 & 6 & 0.1086 & 5 \\
\hline Time to reach stops & 0.1199 & 4 & 0.1033 & 4 & 0.1145 & 3 \\
\hline Need for transfer & 0.0595 & 6 & 0.0632 & 5 & 0.0581 & 6 \\
\hline Fit connection & 0.0385 & 7 & 0.0400 & 7 & 0.0399 & 7 \\
\hline Frequency of lines & 0.1786 & 2 & 0.2039 & 1 & 0.1145 & 4 \\
\hline Limited time of use & 0.1316 & 3 & 0.1585 & 2 & 0.1958 & 1 \\
\hline
\end{tabular}

As shown in Tables 3 and 4, there is a significant difference among the different evaluator groups. Kendall's concordance coefficient $(\mathrm{W})$ has been conducted to detect the degree of agreement among different evaluator groups (passengers, non-passengers, and municipal officials). Based on Table 5, there was a "strong agreement" among other evaluator groups in the first level. 
Table 5. Kendall's coefficient of concordance $(W)$ for level 1.

\begin{tabular}{cccccc}
\hline Criteria & $\begin{array}{c}\text { Rank of } \\
\text { Passenger Side }\end{array}$ & $\begin{array}{c}\text { Rank of } \\
\text { Non-Passenger }\end{array}$ & $\begin{array}{c}\text { Rank of } \\
\text { Municipal Official's }\end{array}$ & $\boldsymbol{R}_{\boldsymbol{i}}$ & $\left(\boldsymbol{R}_{\boldsymbol{i}}-\boldsymbol{R}\right)^{2}$ \\
\hline Approachability & 5 & 5 & 5 & 15 & 36 \\
Directness & 4 & 4 & 4 & 12 & 9 \\
Time availability & 2 & 1 & 2 & 5 & 16 \\
Speed & 1 & 2 & 1 & 9 & 25 \\
Reliability & 3 & 3 & 3 & 0 & $W=0.956$ \\
$N=5$ & $M=3$ & $S=86$ & $R=9$ & & \\
\hline
\end{tabular}

In level 2 (Table 6), Kendall's concordance coefficient (W) also indicates that the agreement is strong among different evaluator groups following the intervals exhibited in Table 6. The rank analysis revealed diverse opinions on the necessary elements that need to be developed for the same public bus transportation system. It can be interpreted through the groups' different interests and motivations (mainly between passengers with maximizing the fleet of buses and municipal representatives with minimizing the total budget) or insufficient expertise or information for the passengers' side.

Table 6. Kendall's coefficient of concordance $(W)$ for level 2.

\begin{tabular}{|c|c|c|c|c|c|}
\hline Criteria & $\begin{array}{c}\text { Rank of } \\
\text { Passenger Side }\end{array}$ & $\begin{array}{c}\text { Rank of } \\
\text { Non-Passenger }\end{array}$ & $\begin{array}{c}\text { Rank of } \\
\text { Municipal Official's }\end{array}$ & $R_{i}$ & $\left(\boldsymbol{R}_{\boldsymbol{i}}-\boldsymbol{R}\right)^{2}$ \\
\hline Distance to stop & 8 & 8 & 8 & 24 & 5.06 \\
\hline Comfort of Stops & 10 & 10 & 10 & 30 & \\
\hline Safety of Stops & 9 & 9 & 9 & 27 & 27.56 \\
\hline Need for transfer & 6 & 5 & 6 & 17 & 22.56 \\
\hline Fit connection & 7 & 7 & 7 & 21 & 0.5625 \\
\hline Frequency of lines & 2 & 1 & 4 & 7 & 217.56 \\
\hline Limited time of use & 3 & 2 & 1 & 6 & 248.06 \\
\hline Journey time & 1 & 3 & 2 & 6 & 248.06 \\
\hline Awaiting time & 5 & 6 & 6 & 14 & 33.06 \\
\hline Time to reach stops & 4 & 4 & 3 & 11 & 115.56 \\
\hline$N=10$ & $M=3$ & $S=710.5$ & $R=21.75$ & \multicolumn{2}{|c|}{$W=0.9569$} \\
\hline
\end{tabular}

Accordingly, this study identified strong agreement and priority among the stakeholder; unlike the previous studies $[9,16,31]$, the pandemic might have rearranged the priorities for the stakeholders.

\section{Conclusions}

On the basis of the results, it can be expected that the calculation of Kendall proved the difference between stakeholders' opinions on public transport. It should be stressed that the Fuzzy-AHP application alone has revealed considerable user preferences. Moreover, the application of the Kendall method has demonstrated that the Kendall approach can recognize a strong link between the three groups for both levels. At the same time, the participants assessed their perceptions in the same questionnaires. It can therefore be stated that in their future transportation strategy, decision makers within the Amman Municipality Transportation Department should share their views with the public.

In general, Fuzzy-AHP amended by Kendall analysis and group coordination has been proven as an appropriate method for evaluating transport participants' demand for system improvement. However, instead of an automatic overall aggregation, a clear distinction among passengers, non-passenger citizens, and municipal officials is advised to get more sophisticated results because of the different motivations and expertise in system development. Under these conditions, it is strongly recommended to apply the Kendall method and Fuzzy-AHP to analyze the distance among the stakeholders' different aspects. 
As a remark for further research, optimization techniques might be selected to create agreement among the different groups on an objective basis and gain a final preference ranking for development factors containing all aspects. A successful application might result in a proper scoring system for tendering transportation projects in which technical cost considerations are integrated and characteristics of the current and future passengers.

This study has a few drawbacks. Firstly, the sample size was small. Secondly, we only had six bus stations due to the movement restriction that could not meet our expectations. Accordingly, the results could not necessarily extend to the whole of the city from this limited area. Thirdly, most of the results were due to compulsory changes. The government constraints caused many changes in the mobility observed, and for Jordanians, they were no option. Fourthly, it is difficult to compare the results with other countries with similar or different pandemic features because their impact is unknown. This study nevertheless contributes to the study of mobility.

Author Contributions: Conceptualization, A.A. and S.D.; methodology, A.A.; validation, A.A., S.D.; formal analysis, A.A.; investigation, A.A.; resources, A.A.; data curation, A.A.; writing-original draft preparation, A.A.; writing-review and editing, A.A. and S.D.; visualization, A.A.; supervision, S.D.; project administration, A.A. Both authors have read and agreed to the published version of the manuscript.

Funding: This research received no external funding.

Institutional Review Board Statement: Not applicable.

Informed Consent Statement: Not applicable.

Data Availability Statement: Not applicable.

Conflicts of Interest: The authors declare no conflict of interest.

\section{References}

1. Moslem, S.; Campisi, T.; Szmelter-Jarosz, A.; Duleba, S.; Nahiduzzaman, K.; Tesoriere, G. Best-Worst Method for Modelling Mobility Choice after COVID-19: Evidence from Italy. Sustainability 2020, 12, 6824. [CrossRef]

2. Duleba, S.; Mishina, T.; Shimazaki, Y. A dynamic analysis on public bus transport's supply quality by using ahp. Transport 2012, 27, 268-275. [CrossRef]

3. Peng, S.-H. Landscape Assessment for Stream Regulation Works in a Watershed Using the Analytic Network Process (ANP). Sustainability 2019, 11, 1540. [CrossRef]

4. Rezaei, J. Best-worst multi-criteria decision-making method. Omega 2015, 53, 49-57. [CrossRef]

5. Rasheed, R.; Javed, H.; Rizwan, A.; Yasar, A.; Tabinda, A.B.; Mahfooz, Y.; Wang, Y.; Su, Y. Sustainability and CDM potential analysis of a novel vs conventional bioenergy projects in South Asia by multi-criteria decision-making method. Environ. Sci. Pollut. Res. 2020, 27, 23081-23093. [CrossRef]

6. Mustajoki, J.; Hamalainen, R.P.; Salo, A. Decision Support by Interval SMART/SWING-Incorporating Imprecision in the SMART and SWING Methods. Decis. Sci. 2005, 36, 317-339. [CrossRef]

7. Mohammadi, M.; Rezaei, J. Bayesian best-worst method: A probabilistic group decision making model. Omega 2020, 96, 102075. [CrossRef]

8. Boujelbene, Y.; Derbel, A. The Performance Analysis of Public Transport Operators in Tunisia Using AHP Method. Procedia Comput. Sci. 2015, 73, 498-508. [CrossRef]

9. Alkharabsheh, A.; Moslem, S.; Duleba, S. Evaluating Passenger Demand for Development of the Urban Transport System by an AHP Model with the Real-World Application of Amman. Appl. Sci. 2019, 9, 4759. [CrossRef]

10. Nassereddine, M.; Eskandari, H. An integrated MCDM approach to evaluate public transportation systems in Tehran. Transp. Res. Part A Policy Pract. 2017, 106, 427-439. [CrossRef]

11. Oubahman, L.; Duleba, S. Review of Promethee method in transportation. Prod. Eng. Arch. 2021, 27, 69-74. [CrossRef]

12. Duleba, S. An ahp-ism approach for considering public preferences in a public transport development decision. Transport 2019, 34, 662-671. [CrossRef]

13. Salais-Fierro, T.E.; Saucedo-Martinez, J.A.; Rodriguez-Aguilar, R.; Vela-Haro, J.M. Demand Prediction Using a Soft-Computing Approach: A Case Study of Automotive Industry. Appl. Sci. 2020, 10, 829. [CrossRef]

14. Duleba, S.; Moslem, S. Examining Pareto optimality in analytic hierarchy process on real Data: An application in public transport service development. Expert Syst. Appl. 2019, 116, 21-30. [CrossRef] 
15. Zhang, H.; Li, X.; Liu, W.; Li, B.; Zhang, Z. An application of the AHP in 3PL vendor selection of a 4PL system. In Proceedings of the 2004 IEEE International Conference on Systems, Man and Cybernetics (IEEE Cat. No.04CH37583), The Hague, The Netherlands, 10-13 October 2005; Volume 2, pp. 1255-1260. [CrossRef]

16. Alkharabsheh, A.; Moslem, S.; Oubahman, L.; Duleba, S. An Integrated Approach of Multi-Criteria Decision-Making and Grey Theory for Evaluating Urban Public Transportation Systems. Sustainability 2021, 13, 2740. [CrossRef]

17. Moslem, S.; Farooq, D.; Ghorbanzadeh, O.; Blaschke, T. Application of the AHP-BWM Model for Evaluating Driver Behavior Factors Related to Road Safety: A Case Study for Budapest. Symmetry 2020, 12, 243. [CrossRef]

18. Obaid, M.; Torok, A.; Ortega, J. A Comprehensive Emissions Model Combining Autonomous Vehicles with Park and Ride and Electric Vehicle Transportation Policies. Sustainability 2021, 13, 4653. [CrossRef]

19. Obaid, M.; Torok, A. Macroscopic Traffic Simulation of Autonomous Vehicle Effects. Vehicles 2021, 3, 12. [CrossRef]

20. Awasthi, A.; Chauhan, S.S. Using AHP and Dempster-Shafer theory for evaluating sustainable transport solutions. Environ. Model. Softw. 2011, 26, 787-796. [CrossRef]

21. Awasthi, A.; Chauhan, S.S.; Omrani, H. Application of fuzzy TOPSIS in evaluating sustainable transportation systems. Expert Syst. Appl. 2011, 38, 12270-12280. [CrossRef]

22. Al-Atawi, A.M.; Kumar, R.; Saleh, W. Transportation sustainability index for tabuk city in saudi arabia: An analytic hierarchy process. Transport 2015, 31, 47-55. [CrossRef]

23. Chou, C.-C.; Ding, J.-F. Application of an Integrated Model with MCDM and IPA to Evaluate the Service Quality of Transshipment port. Math. Probl. Eng. 2013, 2013, 656757. [CrossRef]

24. Chien-Chang, C. Evaluating the quality of airport service using the fuzzy multi-criteria decision-making method: A case study of Taiwanese airports. Expert Syst. 2011, 29, 246-260. [CrossRef]

25. UNHCR. UN Fact Sheet. 2012. Available online: https://reporting.unhcr.org/sites/default/files/UNHCRJordanFactSheetNovember2019_0.pdf (accessed on 5 May 2021).

26. Amerian Public Transportation Association. Economic Impact of Public Transportation Investment. 2014. Available online: https:/ / www.apta.com/wp-content/uploads/Resources/resources/reportsandpublications/Documents/Economic-ImpactPublic-Transportation-Investment-APTA.pdf (accessed on 5 May 2021).

27. Le-Klähn, D.-T.; Hall, C.M. Tourist use of public transport at destinations-A review. Curr. Issues Tour. 2015, 18, 785-803. [CrossRef]

28. Al-Masaeid, H.R. Traffic accidents in Jordan. Jordan J. Civ. Eng. 2009, 3, 331-343.

29. Shtayat, A.; Abu Alfoul, M.; Moridpour, S.; Al-Hurr, N.; Magableh, K.; Harahsheh, I. Waiting Time of Public Transport Passengers in Jordan: Magnitude and Cost. Open Transp. J. 2019, 13, 227-235. [CrossRef]

30. Smadi, A.; Management, T.; Municipality, G.A. Training on SUMP: Feedback from Jordan. Brest. 2013. Available online: https:/ / civitas.eu/sites/default/files/documents/Jordan-AymanSamdi.pdf (accessed on 5 May 2021).

31. Moslem, S.; Alkharabsheh, A.; Ismael, K.; Duleba, S. An Integrated Decision Support Model for Evaluating Public Transport Quality. Appl. Sci. 2020, 10, 4158. [CrossRef]

32. Farooq, D.; Moslem, S.; Tufail, R.F.; Ghorbanzadeh, O.; Duleba, S.; Maqsoom, A.; Blaschke, T. Analyzing the Importance of Driver Behavior Criteria Related to Road Safety for Different Driving Cultures. Int. J. Environ. Res. Public Health 2020, $17,1893$. [CrossRef]

33. Mardani, A.; Zavadskas, E.K.; Khalifah, Z.; Jusoh, A.; Nor, K.M. Multiple criteria decision-making techniques in transportation systems: A systematic review of the state of the art literature. Transport 2015, 31, 359-385. [CrossRef]

34. Sun, C.-C. A performance evaluation model by integrating fuzzy AHP and fuzzy TOPSIS methods. Expert Syst. Appl. 2010, 37, 7745-7754. [CrossRef]

35. Gumus, A.T. Evaluation of hazardous waste transportation firms by using a two step fuzzy-AHP and TOPSIS methodology. Expert Syst. Appl. 2009, 36, 4067-4074. [CrossRef]

36. Hsieh, T.-Y.; Lu, S.-T.; Tzeng, G.-H. Fuzzy MCDM approach for planning and design tenders selection in public office buildings. Int. J. Proj. Manag. 2004, 22, 573-584. [CrossRef]

37. Saaty, T.L. A scaling method for priorities in hierarchical structures. J. Math. Psychol. 1977, 15, 234-281. [CrossRef]

38. Kendall, M.G.; Smith, B.B. The Problem of \$m\$ Rankings. Ann. Math. Stat. 1939, 10, 275-287. [CrossRef]

39. Gronau, W.; Kagermeier, A. Key factors for successful leisure and tourism public transport provision. J. Transp. Geogr. 2007, 15, 127-135. [CrossRef]

40. Xu, P.; Wang, W.; Wei, C. Economic and Environmental Effects of Public Transport Subsidy Policies: A Spatial CGE Model of Beijing. Math. Probl. Eng. 2018, 2018, 3843281. [CrossRef] 